\title{
MC4R Mutation in Early-onset Severe Childhood Obesity-Genotype-phenotype Correlation
}

\author{
Shweta Birla, ${ }^{1}$ Deepak Khandelwal, ${ }^{2}$ Arundhati Sharma, ${ }^{1}$ and Rajesh Khadgawat ${ }^{3}$ \\ 1. Laboratory of Cytomolecular Genetics, Department of Anatomy, All India Institute of Medical Sciences, New Delhi, India; 2. Department of Diabetes \\ and Endocrinology, Maharaja Agrasen Hospital, Punjabi Bagh, New Delhi, India; 3. Department of Endocrinology and Metabolism, All India Institute of \\ Medical Sciences, New Delhi, India
}

DOI: https://doi.org/10.17925/USE.2017.13.02.69

$\mathrm{M}$ elanocortin-4 receptor (MC4R; OMIM\#155541) encodes a 332-amino acids protein possessing typical G-protein-coupled receptors' (GPCRS) structural design having three intact and functional domains, mutations which lead to the most recurrent type of monogenic obesity. Methods: We report here a case of a 5-year-old boy from Iraq who presented to the clinic for evaluation of progressive weight gain since he was 6 months of age. There were no symptoms of hypothalamic dysfunction except increase in appetite. His height was $120 \mathrm{~cm}$ (97th centile of the Centers for Disease Control and Prevention [CDC] growth chart, mid parental height was 50th centile), weight was $57 \mathrm{~kg}$ (>97th centile on CDC chart) and body mass index was $39.6 \mathrm{~kg} / \mathrm{m}^{2}$ ( $>97$ th centile on CDC chart). A monogenic cause of obesity was strongly suspected in view of early onset severe childhood obesity. Results: Mutation screening of MC4R revealed a homozygous isoleucine by arginie at codon 69 (I69R) mutation in the patient, while his father was heterozygous for this mutation. Conclusion: We describe a monogenic form of obesity with characteristic presentation due to I69R MC4R mutation inherited as an autosomal recessive condition. The finding is different from previous reports which have documented this mutation to be inherited in a dominant manner. The findings of the present study reiterate the complex nature of obesity with possible involvement of modifier genes and/or genetic heterogeneity in its causation.

\section{Keywords}

Monogenic obesity, melanocortin-4 receptor (MC4R), hypothalamic obesity, childhood onset obesity, mutation, screening

Disclosure: Shweta Birla, Deepak Khandelwal, Arundhati Sharma, and Rajesh Khadgawat have nothing to declare in relation to this article. No funding was received in the publication of this article.

Compliance with Ethics: All procedures were followed in accordance with the responsible committee on human experimentation and with the Helsinki Declaration of 1975 and subsequent revisions, and informed consent was received from the patient involved in this case study.

Authorship: All named authors meet the International Committee of Medical Journal Editors (ICMJE) criteria for authorship of this manuscript, take responsibility for the integrity of the work as a whole, and have given final approval to the version to be published. Shweta Birla and Deepak Khandelwal contributed equally.

open Access: This article is published under the Creative Commons Attribution Noncommercial License, which permits any noncommercial use, distribution, adaptation, and reproduction provided the original author(s) and source are given appropriate credit.

Received: August 18, 2017

Accepted: October 16, 2017

Citation: US Endocrinology, 2017;13(2):69-71

Corresponding Author: Arundhati Sharma, Department of Anatomy, All India Institute of Medical Sciences, New Delhi, India. E: arundhatisharma1@gmail.com
Obesity is a complex and multifactorial condition caused by various behavioral and environmental factors, socioeconomic background, and genetic susceptibility. The leptin-melanocortin system has a well-established role in energy homeostasis and deficiencies of the vital molecules of the pathway due to defects in the genes encoding those results into a monogenic form of obesity. ${ }^{1}$

The most recurrent type of monogenic obesity is caused by mutations in the gene that codes for the melanocortin-4 receptor (MC4R). Expressed primarily in neurons, MC4R is a G protein-coupled receptor and is known to mediate the anorexigenic effects of leptin, reducing food intake and increasing energy expenditure. It responds to $\alpha$-melanocyte-stimulating hormone ( $\alpha$-MSH) an agonist leading to initiation of receptor activity and restraining food intake, whereas sensitizing with an antagonist agouti-related peptide (AgRP) has the reverse effect. ${ }^{2}$ We report here a case of severe early-onset childhood obesity due to homozygous I69R MC4R mutation.

\section{Materials and methods Case presentation}

A 5-year-old boy from Iraq presented to the clinic for evaluation of progressive weight gain since the age of 6 months (Figure 1A). He was a product of consanguineous marriage and his perinatal history was unremarkable. Developmental milestones were appropriate for his age and there were no symptoms suggestive of neuro-developmental abnormalities. There were no symptoms of hypothalamic dysfunction, except increase in appetite, and no family history of morbid obesity except for type 2 diabetes (T2D) in one of his maternal uncles. His father's height and weight was $171 \mathrm{~cm}$ and $82 \mathrm{~kg}$, respectively. His mother's height and weight was $165 \mathrm{~cm}$ and $60 \mathrm{~kg}$, respectively. His height was $120 \mathrm{~cm}$ (97th centile of the Centers for Disease Control and Prevention [CDC] growth chart, midparental height 50th centile), weight was $57 \mathrm{~kg}$ (>97th centile on CDC chart), and body mass index (BMI) was $39.6 \mathrm{~kg} / \mathrm{m}^{2}$ (>97th centile on CDC chart). Blood pressure was 80/52 mmHg (right arm in sitting position). On examination he was prepubertal and had acanthosis over the neck and axillary region. Hemogram, renal function test, and serum electrolytes were within the normal range. Liver function test showed evidence of transaminitis (Table 1). Tests were negative for hepatitis B surface antigen (HBSA) and anti-hepatitis C virus (HCV) antibodies. Ultrasonography 
Figure 1: Patient with early-onset severe childhood obesity and sequencing electropherograms

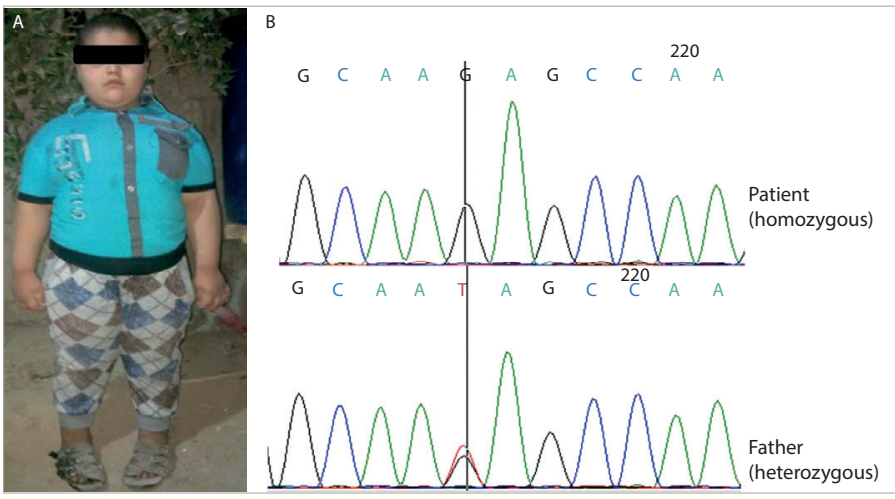

Patient with early-onset severe childhood obesity (A) and sequencing electropherograms (B) showing $T$ to $G$ transition leading to replacement of isoleucine by arginie at codon 69 (I69R), homozygous in patient (upper panel) and heterozygous in father (lower panel).

Table 1: Values of the biochemical tests of the patient

\begin{tabular}{|l|l|l|}
\hline $\begin{array}{l}\text { Serial } \\
\text { No. }\end{array}$ & Biochemical test & Results \\
\hline 1 & Hemoglobin $(\mathrm{g} / \mathrm{dL})$ & 14 \\
\hline 2 & Serum SGPT $(<50 \mathrm{IU} / \mathrm{L})$ & 84 \\
\hline 3 & Serum SGOT $(<50 \mathrm{IU} / \mathrm{L})$ & 72 \\
\hline 4 & Total cholesterol $(\mathrm{mg} / \mathrm{dL})$ & 114 \\
\hline 5 & LDL cholesterol $(\mathrm{mg} / \mathrm{dL})$ & 71.6 \\
\hline 6 & HDL cholesterol $(\mathrm{mg} / \mathrm{dL})$ & 24 \\
\hline 7 & Serum triglyceride $(\mathrm{mg} / \mathrm{dL})$ & 92 \\
\hline 8 & TOtal T4 $(5.1-14.1 \mu \mathrm{g} / \mathrm{dl})$ & 8.33 \\
\hline 9 & TSH $(0.27-4.2 \mu \mathrm{U} / \mathrm{ml})$ & 4.12 \\
\hline 10 & 8 am cortisol $(6.2-19.4 \mu \mathrm{g} / \mathrm{dl})$ & 20.4 \\
\hline 11 & Plasma ACTH $(7.2-63.3 \mathrm{pg} / \mathrm{ml})$ & 27.80 \\
\hline 12 & ONDST cortisol $(<1.8 \mu \mathrm{g} / \mathrm{dl})$ & 1.44 \\
\hline 13 & LDDST cortisol $(<1.8 \mu \mathrm{dg} / \mathrm{dl})$ & 0.99 \\
\hline
\end{tabular}

ACTH = adrenocorticotropic hormone; $H D L$ = high-density lipoprotein; $L D D S T=10 w$-dose dexamethasone suppression test; $L D L=$ low-density lipoprotein; ONDST = overnight dexamethasone suppression test: $S G O T=$ serum glutamic-oxalacetic transaminase SGPT = serum g/utamic pyruvic transaminase; $T S H=$ thyroid-stimulating hormone.

of the abdomen showed grade 1 fatty liver with mild hepatomegaly. Noncontrast computed tomography (NCCT) images of the abdomen showed mild hepatomegaly and diffused fatty liver with normal bilateral adrenals. There was no evidence of other endocrine dysfunction (Table 1). Workup for hypercortisolism was negative. Magnetic resonance imaging (MRI) scan of the pituitary-hypothalamic area and fundus examination were also normal. A monogenic cause of obesity was strongly suspected in view of early-onset severe childhood obesity.

\section{Genetic screening}

Detailed family history and pedigree information was collected. Peripheral blood sample was drawn in ethylenediaminetetraacetic acid for molecular investigations after taking informed consent from the patient and his father. Genomic DNA was extracted using standard salting out protocol and subjected to polymerase chain reaction amplification of the MC4R gene with primers described previously ${ }^{3}$ using 90-100 ng DNA, 1.25 mM
$\mathrm{MgCl}_{2}, 0.25 \mathrm{mM}$ of each of the deoxynucleotide triphosphates (dNTPs) (Invitrogen, Carlsbad, CA, US), 10 pM of each primer and 0.5 units of Taq polymerase (Invitrogen, Carlsbad, CA, US) in a 25 ul volume mixture using thermocycler Applied Biosystems (ABI) 9700 (Applied Biosystems, Foster City, CA, US).

\section{Sequencing and mutation analysis}

All the amplified products were purified using Qiagen kits (Qiagen, $\mathrm{GmbH}$, Hilden, Germany), sequenced using BigDye Terminator Mix version 3.1 (Applied Biosystems, Foster City, CA, US) and analyzed on an ABI-3100 Genetic Analyzer (ABI). Nucleotide sequences were compared with the published CDNA sequences of MC4R (GenBank accession number ENSG00000166603) gene.

\section{Results}

Direct sequencing of the MC4R gene in the patient revealed a homozygous isoleucine by arginie at codon 69 (I69R) mutation (Figure 1B). His father was heterozygous for this mutation.

\section{Discussion}

This study reports on a severe form of early-onset childhood obesity due to homozygous I69R MC4R mutation. The father, who was heterozygous for this mutation, did not show any morbid obesity, whereas the mother was unavailable for testing.

MC4R (OMIM\#155541) encodes a 332 amino acids protein possessing the typical GPCR structural design, having three intact and functional domains; extracellular $\mathrm{N}$-terminus, 7 transmembrane (TM) domain (seven domains connected by intracellular and extracellular loops) and an intracellular C terminus.

The presence of these three intact domains is necessary for stability of the receptor protein, its integration on the cell surface, correct folding, assembly, and its important role in binding to the extracellular ligands activating specific signaling pathways mediated by $\mathrm{G}$ proteins. ${ }^{4}$

More than 150 functionally relevant mutations in MC4R have been identified so far. ${ }^{5.6}$ In vitro analysis has shown that most of these mutations lead to either total or partial loss of receptor function..$^{78}$ Studies on various ethnic groups described so far revealed that the majority of MC4R mutations are inherited as autosomal-dominant trait with a single copy of the mutant allele whereas homozygous carriers are very rare and exhibit a more severe phenotype. Some studies have shown that heterozygous mutation carriers of the MC4R gene may or may not be obese, while homozygous individuals are all extremely obese. 910

The 169R mutation was first described in a study on large number of obese patients from Norway. The mutation was identified in heterozygous state in pediatric patients with severe childhood obesity." It was not observed in adult obese patients.

The functional study on MC4R mutation revealed that 169R mutant receptor had no measurable binding with the ligands, giving no response to agonist/ antagonist stimulation demonstrating that 169 is an important residue for cell surface expression located in the first trans membrane domain. ${ }^{12}$

Genetic findings in the present report are unique, as the patient with severe obesity has 169R mutation present in homozygous state while 
his father, a heterozygous carrier, does not show any signs of the condition. This finding is in contrast with a previous report wherein a single copy of the I69R mutation was sufficient to cause severe childhood-onset obesity.11

Behavioral patterns in children, such as eating larger meals and viewing television have been shown to be associated with MC4R mutations to some extent. Similar behavior patterns have been seen in our case, which is in accordance with published reports. ${ }^{13,14}$
In conclusion, we describe a monogenic form of obesity with characteristic presentation due to $169 \mathrm{R}$ MC4R mutation inherited as an autosomal recessive condition, requiring two mutant alleles to express. The father, who was a carrier of the mutation, was normal and did not show any obesityrelated symptoms, which is in contrast to previous reports.

The findings of the present study reiterate the complex nature of obesity, with the possible involvement of modifier genes and genetic heterogeneity in its causation.
1. Lee YS, Melanocortin 3 receptor gene and melanocortin 4 receptor gene mutations: the Asian Perspective, Diabetes Metab Res Rev, 2012:28:26-31.

2. Cone RD, Anatomy and regulation of the central melanocortin system, Nat Neurosci, 2005;8:571-8.

3. Suviolahti E, Ridderstråle M, Almgren P, et al., Proopiomelanocortin gene is associated with serum leptin levels in lean but not in obese individuals, Int J Obes Relat Metab Disord 2003;27:1204-11.

4. Gantz I, Fong TM, The melanocortin system, Am J Physiol Endocrinol Metab, 2003:284:E468-74.

5. Tao YX, The melanocortin-4 receptor: Physiology, pharmacology, and pathophysiology, Endocr Rev, 2010;31:506-43.

6. Tao YX, Mutations in melanocortin- 4 receptor and human obesity,
Prog Mol Biol Trans/ SCi, 2009:88:173-204.

7. Tao YX, Molecular mechanisms of the neural melanocortin receptor dysfunction in severe early onset obesity, $\mathrm{Mol}$ Cell Endocrinol, 2005:239:1-14.

8. Tao YX, Segaloff DL, Functional characterization of melanocortin- 4 receptor mutations associated with childhood obesity, Endocrinology, 2003;144:4544-51.

9. Vaisse C, Clement K, Durand E, et al., Melanocortin-4 receptor mutations are a frequent and heterogeneous cause of morbid obesity I Clin Invest 2000:106:253-62.

10. Hinney A, Hohmann $S$, Geller F, et al., Melanocortin-4 receptor gene: case-control study and transmission disequilibrium test confirm that functionally relevant mutations are compatible with a major gene effect for extreme obesity, I Clin Endocrinol Metab,
2003:88:4258-67.

11. Wangensteen $T$, Kolsgaard ML, Mattingsdal M, et al., Mutations in the melanocortin 4 receptor (MC4R) gene in obese patients in Norway, Exp Clin Endocrinol Diabetes, 2009;117:266-73.

12. Wang $Z Q$, Tao $Y X$, Functional Studies on Twenty Novel Naturally Occurring Melanocortin-4 Receptor Mutations, Biochim Biophys Acta, 2011:1812:1190-9.

13. Faroogi IS, Keogh JM, Yeo GS, et al., Clinical spectrum of obesity and mutations in the melanocortin 4 receptor gene, N Eng/ J Med, 2003:348:1085-95.

14. Plomin R, Corley R, Carey G, et al., Individual differences in television viewing in early childhood: nature as well as nurture Psychol Sci, 1990;1:371-7. 